\title{
SEN2-AGRI - CROP TYPE MAPPING PILOT STUDY USING SENTINEL-2 SATELLITE IMAGERY IN INDIA
}

\author{
Vijayasekaran Duraisamy *1 \\ ${ }^{1}$ The WOTR Centre for Resilience Studies (W-CReS), Watershed Organisation Trust, Pune, India - vijay.duraisamy@wotr.org.in
}

Commission III, WG III/10

KEY WORDS: Remote Sensing, Cropland, Sentinel-2, Crop type mapping, Random forest, India

\begin{abstract}
:
Large-scale mapping and monitoring of agriculture land use are very important. It helps in forecast crop yields, assesses the factors influencing the crop stress and estimate the damage due to natural hazards. Also, more essentially, aids in calculating the irrigation water demand at the farm level and better water resource management. Recent developments in remote sensing satellite sensors spatial and temporal resolutions, global coverage and open access such as Sentinel-2, created new possibilities in mapping and monitoring land use/land cover features. The present study investigated the performance and applicability of Sen2-Agri system in the heterogeneous cropping system for operational crop type mapping at parcel resolution using time series Sentinel-2 multispectral satellite imagery. The parcel level crop type information was collected in the field by systematic sampling and used to train and validate the random forest (RF) classification in the system. The classification accuracy varied from $57 \%$ to $86 \%$ for different major crops. The overall classification accuracy was $70 \%$ with KAPPA index of $61 \%$. The very small agriculture field size and persistent cloud cover are the major constraint to the improvement of classification accuracy. Combination of the time series imagery from multiple earth observation satellites for the monsoon cropping season and development of a robust system for in-situ data collection will further increase the mapping accuracy. Sen2-Agri system has the potential to handle a large amount of earth observation data and can be scaled up to the entire country, which will help in the efficient monitoring of crops.
\end{abstract}

\section{INTRODUCTION}

Climate change affects the global agriculture and food security in complex ways (Schmidhuber and Tubiello, 2007). In the context of climate change and food security, the region-specific crop inventories are important which helps in identifying factors influencing crop stress, simulate and predict crop yield changes and analyses the market risks (Doraiswamy et al., 2003; Monfreda et al., 2008; Mittal, 2012). There are multiple global agriculture monitoring systems are in place for decades for agriculture monitoring and early warning (Becker-Reshef et al., 2010). Fritz et al., (2019) compared the eight global agricultural monitoring systems and highlighted the uncertainties in the crop type maps, which are viewed as critically important. Remote sensing data is adequately used for cropland mapping at regional (Biradar and Xiao, 2011; Xiong et al., 2017; Teluguntla et al., 2018) and global scale (Pittman et al., 2010; Thenkabail et al., 2010; Matton et al., 2015). Moderate spatial resolution remote sensing data is exploited in mapping global rain-fed area (Biradar et al., 2009; Salmon et al., 2015) and irrigated area (Thenkabail et al., 2009; Siebert et al., 2015), crop type (Zheng et al., 2015; Asgarian et al., 2016; Kussul et al., 2017) and crop condition monitoring (Wu et al., 2015). Nevertheless, the available cropland maps are of coarse spatial resolution and lack of sufficient accuracy for use in assessment and planning purposes (Fritz et al., 2013). However, the launch of Sentinel series satellites has created tremendous possibilities for improving the accuracy in cropland mapping and efficient agriculture monitoring. The Sentinel-2 (S-2) twin satellites equipped with Multispectral Imager (MSI) has the advantage of lesser revisiting time (5 days), high spatial resolution (10 meters), and a number of bands in the red-edge spectrum. Attempts were made to combine Sentinel-2 and Landsat satellite data to produce hybrid imagery to improve the number of observations and obtain cloud-free composite for crop mapping at a regional scale (Skakun et al., 2017; Griffiths et al., 2019). Moreover, the Copernicus open-access hub provided full free access to sentinel series satellite imagery from 2014 onwards and published more than 4.81 pebibyte volume of data (European Space Agency, 2018). This creates a new challenge and opportunity for developing automated systems that handle a large volume of remote sensing data and efficient information extraction. At the same time, the cloudprocessing facilities along with the application of artificial intelligence and machine learning algorithms getting more attention in remote sensing. It benefits the satellite data processing by optimization in handling a large volume of data, automation, and information extraction (Lary et al., 2016). The well-established machine learning methods such as support vector machine (SVM) and random forest (RF) are adequately used in crop type mapping because of their capability to produce accurate classification results with limited training samples and high computational efficiency (Mathur and Foody, 2008; Löw et al., 2013; Waldner et al., 2015). Inglada et al., (2015) evaluated the performance of an open-source operational system processing chain "Sentinel-2 for Agriculture" funded by the European Space Agency (ESA) for automated crop type mapping. The system evaluated with processing strategies including RF and SVM classifiers for crop mapping in multiple sites and the results were compatible with the operational production of crop type maps at country scale. Later the system was named as "Sen2-Agri" operational standalone processing

\footnotetext{
* Corresponding author
} 
with predefined sequential operations for near-real-time agriculture monitoring at parcel resolution using Sentinel-2 and Landsat data and tested in various cropping systems in the world (Defourny et al., 2019). The objective of the present study is to investigate the performance and applicability of Sen2-Agri system in the heterogeneous cropping system in India for operational crop type mapping at parcel resolution.

\section{STUDY AREA AND DATA}

The study is piloted in the Sangamner administrative block of Ahmednagar district, Maharashtra, India. It is located between $74^{\circ} 01^{\prime} 10^{\prime \prime}-74^{\circ} 27^{\prime} 20^{\prime \prime} \mathrm{E}$ and $19^{\circ} 12^{\prime} 09^{\prime \prime}-19^{\circ} 46^{\prime} 51^{\prime \prime} \mathrm{N}$, covers a geographical area of $1,688 \mathrm{~km}^{2}$. The climatic zone of the study area is 'semi-arid' with a mean annual rainfall of 480 $\mathrm{mm}$. Agriculture in this region is predominantly rainfed situated in northern and southern higher elevation profiles. The central part of the study area along the Rivers Pravara and Mula are concentrated with irrigated cropping (Figure 1).

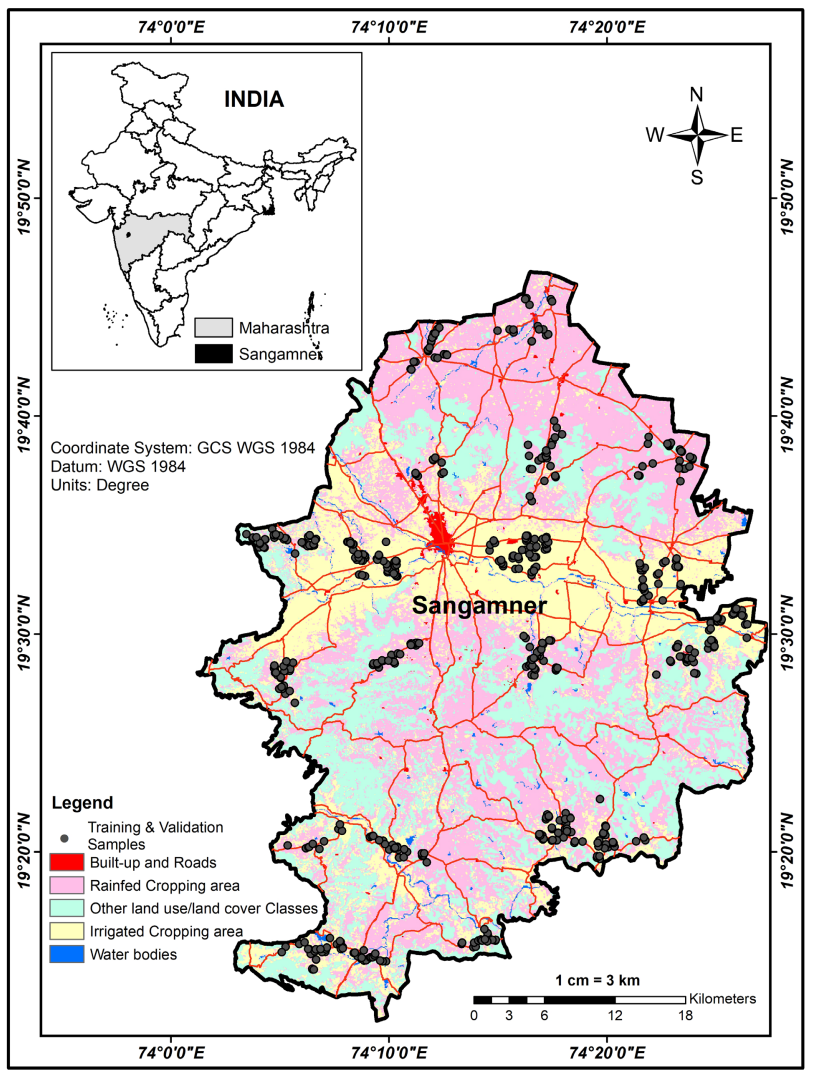

Figure 1. Location of the study area and training samples

In this region crops are cultivated during three seasons: (i) Kharif (July-October, monsoon crops), (ii) Rabi (OctoberMarch, winter crops), and (iii) Zaid (March-June, summer crops). Major crops cultivated in the rainfed region include pearl millet, maize, onion, sorghum, soybean, and the irrigated region farmers grow water-intensive crops such as sugarcane, pomegranate, and fodder crops (alfalfa).

The S2 series Level-1 satellite imagery pertaining to monsoon (Kharif) cropping season of the area was downloaded from Copernicus open-access hub (https://scihub.copernicus.eu). The dates and cloud cover details of the scenes used in this study are provided in Table 1. Study region has persistent high cloud cover during the Kharif season thus the scenes covered with more than $90 \%$ cloud cover are excluded. S-2 satellites acquire data on 13 spectral bands in the visible and near infrared (VNIR) and shortwave infrared (SWIR) with multiple spatial resolutions including 10m (4 bands), 20m (6 bands) and 60m (3 bands).

\begin{tabular}{|c|c|c|}
\hline $\begin{array}{c}\text { Satellite - } \\
\text { sensor }\end{array}$ & Date & $\begin{array}{c}\text { Cloud cover } \\
\text { Percentage }\end{array}$ \\
\hline S2A-MSI & $02-$ Sep-2018 & 65 \\
\hline S2A-MSI & 12 -Sep-2018 & 13 \\
\hline S2A-MSI & $02-$ Oct-2018 & 09 \\
\hline S2B-MSI & $07-$ Oct-2018 & 0 \\
\hline S2A-MSI & 12 -Oct-2018 & 0 \\
\hline
\end{tabular}

Table 1. S-2 satellite imagery used in this study

The crop type in-situ data were collected at parcel level during the end of the growing season (October 2018) to perform the training and validation of image classification. The handheld GPS Garmin-eTrex ${ }^{\circledR} 20 \times$ with 2-3 m of location accuracy was used to geotag the crop type information. In total 535 parcel data for 6 major crops were collected systematically covering the entire study area (Figure.1). Training samples of nonagricultural land cover classes were obtained by visual interpretation of very-high-resolution satellite data of Google Earth comparing with S-2 imagery.

\section{METHODS}

The methodology workflow of Sen2-Agri system used in this study is proved below in Figure.2.

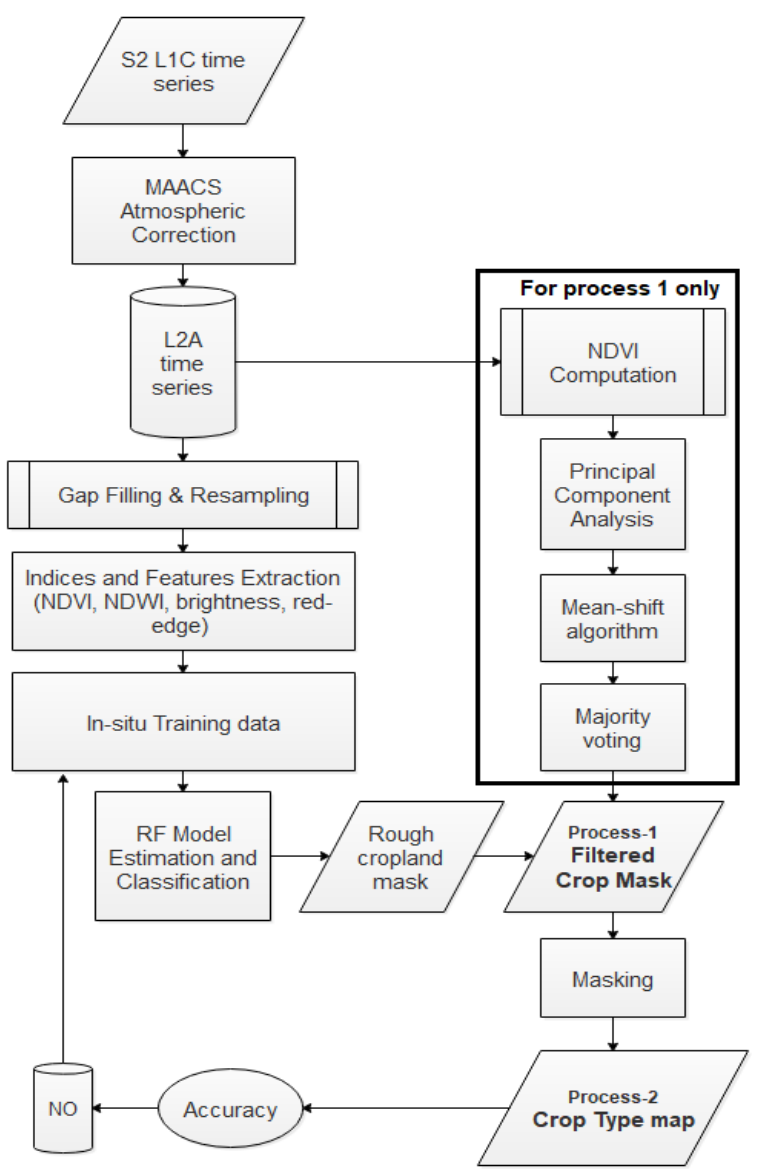

Figure 2. Methodology workflow of Sen2-Agri system 
Sen2-Agri system provides a set of independent image processing modules, which rely on open-source Orfeo Toolbox (OTB). The process chain with two options i) automated execution using an Orchestrator manager which requires high computing power and ii) manual execution of modules. The detailed description of the modules and the system is available at Defourny et al., (2019). In the present study, the modules are manually executed for temporal synthesis processing, crop mask, and crop type map.

\subsection{Pre-processing}

The S2 level-1C series data is processed with S2-level 2 module MACCS (Multi-sensor Atmospheric Correction and Cloud Screening)-ATCOR(Atmospheric and Topographic Correction) joint algorithm known as MAJA (MAJA, 2017) module which detects the clouds and their shadows, and estimates aerosol optical thickness (AOT), water vapour and corrects for the atmospheric effects. Further, in the L2A series, the clouds and cloud shadows pixels were replaced with the 5-day temporal grid by linear interpolation and gap filling.

\subsection{Crop mask and Crop Type Mapping}

The gap-filled data was used to compute various indices including NDVI, NDWI, brightness, and red-edge and stacked with temporal surface reflectance products. The in situ data and the indices are then used to train the RF classifier. NDVI time .series from L2A individual scenes are computed to perform the majority voting for producing optimal crop mask

Layer (L4A). The process chain of gap filling, feature extraction and RF classification model training using in situ data and classification will be repeated for process 2 crop type mapping (L4B). The crop mask created during process 1 used for masking noncropland area.

Table 2. F1-Scores and classification accuracy of crop type map

\subsection{Accuracy Assessment}

In total, 535-crop parcel sample were collected for training and validation purpose of 6 major crops. The samples were randomly split into calibration (75\%) and validation (25\%) sets. Confusion error matrix will be calculated with the process chain to understand the overall, user and producer accuracies. Overall accuracy was calculated to an agreement between the map and the reference information with KAPPA index. The F1-Score also calculated for the crop type classes based on producer and user accuracies (Powers 2011).

\section{RESULTS}

\subsection{Accuracy Performance}

The accuracy assessment results of RF classification at the crop type map is provided in Table 2 . The results showed the overall accuracy of $70 \%$ with KAPPA index of $61 \%$. The higher classification accuracy of $86 \%$ attained by Soybean class with F1-Score of 0.64 . The lowest classification accuracy observed in Maize with $57 \%$ class accuracy and the F1-Score of 0.34 . The possible reason for the lower classification accuracy is mainly due to the size of agricultural fields in the study area, smaller amount of training samples and cloud cover.
The average field size of crops pearl millet, fodder, maize, pomegranate, soybean, sugarcane is 0.48 ha, 0.45 ha, 0.29 ha, 0.27 ha, 1.1 ha, and 0.58 ha respectively. The important Kharif months July to August is completely covered with cloud cover and the imagery used in this study pertaining to early September also have the cloud cover of almost $63 \%$.

\begin{tabular}{|c|c|c|c|}
\hline Crop class & $\begin{array}{c}\text { Cropland } \\
\text { samples }\end{array}$ & $\begin{array}{c}\text { F1- } \\
\text { score }\end{array}$ & $\begin{array}{c}\text { Classification } \\
\text { accuracy (\%) }\end{array}$ \\
\hline Pearl Millet & 80 & 0.73 & 61 \\
\hline fodder & 84 & 0.73 & 61 \\
\hline Maize & 29 & 0.34 & 57 \\
\hline pomegranate & 165 & 0.72 & 75 \\
\hline soybean & 18 & 0.64 & 86 \\
\hline sugarcane & 159 & 0.74 & 80 \\
\hline
\end{tabular}

\subsection{Crop Mask and Crop Type Map}

The crop mask classification accuracy of cropland and noncropland classes are $84 \%$ and $91 \%$ respectively. The binary crop mask map of Sangamner with cropland and non-cropland is shown in Figure 3. MAJA processer extracted the bad quality pixels with cloud/cloud shadow and flagged the all S-2 series imagery. The problematic pixels were further replaced by linear interpolation and gap filling fusing good pixels from the timeseries and which created the possibility to develop a cloud fee composite S-2 series in Kharif season and it is used for crop type mapping.

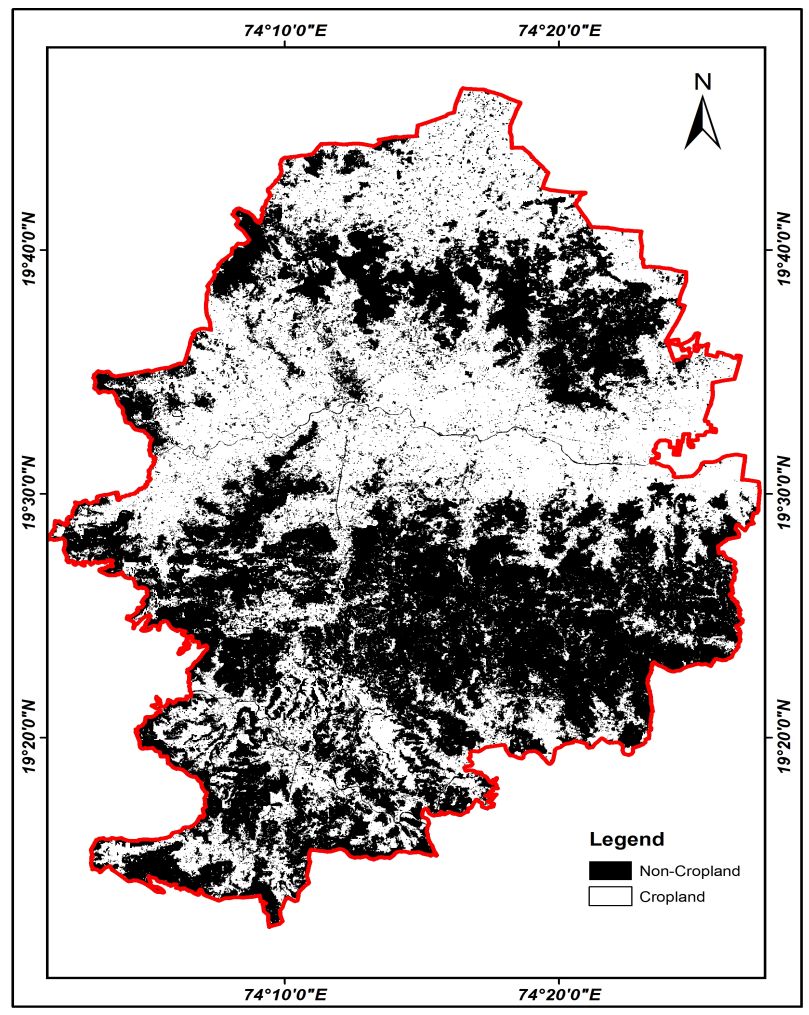

Figure 3. Crop mask created from S-2 series imagery

The second process chain crop type mapping produced the $10 \mathrm{~m}$ spatial resolution crop type map of six major crops in the 
rainfed and irrigated area of Sangamner block and shown in Figure 4.

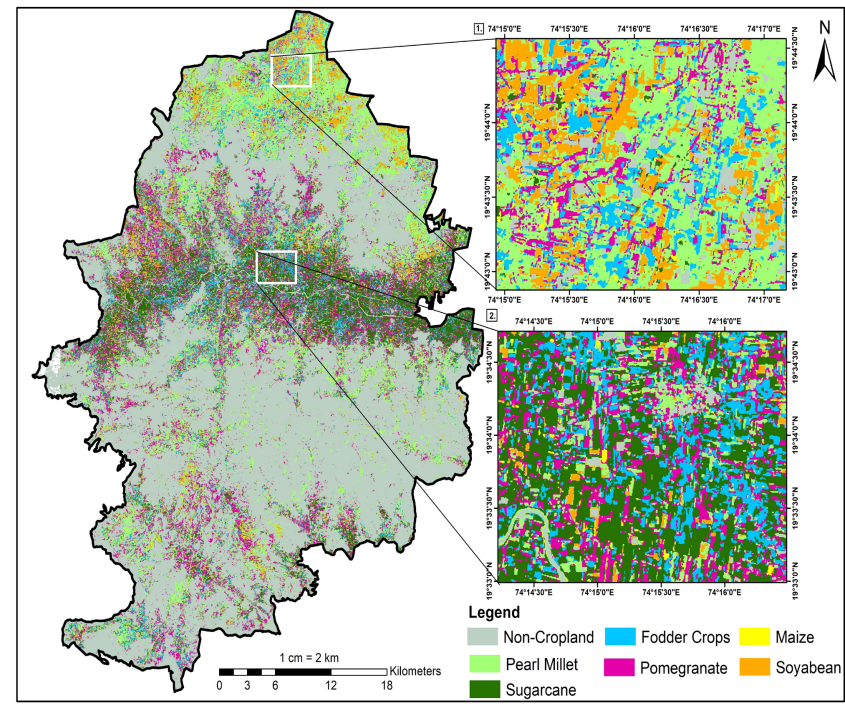

Figure 4. Crop type map (10m) obtained using RF classification. Inset 1 shows the crops of rainfed and inserts 2 shows the irrigated area

\begin{tabular}{|c|c|}
\hline Crop & Area in ha \\
\hline Pearl Millet & 32,140 \\
\hline fodder & 9,784 \\
\hline maize & 1,692 \\
\hline pomegranate & 19,632 \\
\hline soybean & 5,149 \\
\hline sugarcane & 15,349 \\
\hline Total & 83,746 \\
\hline
\end{tabular}

Table 3. Cultivated area of major crops in Kharif 2018

The rainfed region with comparatively larger field size and less heterogeneity of crops produced high classification accuracy. In the irrigated cultivation area the diversity of crops are very high with smaller field size and it created difficulty in separation of crops in smaller field size. For example, a number of maize crop pixels were classified as sugarcane and the intermixing of pomegranate and sugarcane was noticed.

\section{CONCLUSIONS}

The study tested the capability of the free and open-source Sen2-Agri system to discriminate six major crops in the heterogeneous cropping system using a limited number of field samples and S-2 series multispectral satellite imagery. The overall classification accuracy was $70 \%$ with KAPPA index of $61 \%$ attained using RF classification. The classification accuracy of crop types varied from $57 \%$ to $86 \%$. The crop type maps are essential for estimating the loss and damage in case of natural disasters like floods, drought, and pest attacks. Further the crop type database with loss data aids in index-based insurance and improve the efficiency in insurance subsidy payouts. More importantly, the irrigation water resources management require information on cropping patterns to prepare optimal water allocation decisions. However, the classification accuracy of the crop type mapping was hampered due to small agriculture field size and persistent cloud cover in the area. Combination of the time series imagery from multiple earth observation satellites for the monsoon-cropping season possibly increase the chances of getting the cloud-free composite. Furthermore, the development of a robust system for in-situ data collection will further increase the mapping accuracy. The improvement in the accuracy will aid in operationalizing the earth observation for near-real-time agriculture monitoring.

\section{ACKNOWLEDGEMENTS}

The Author acknowledges the ESA Copernicus open-access hub (https://scihub.copernicus.eu/) for providing free access to $\mathrm{S}-2$ series satellite data. The author is grateful to Sen2-Agri (http://www.esa-sen2agri.org) team for make available of the system free and open source. Also, acknowledge the support provided by Mr. Ajit Jadhav during in-situ data collection. And special thanks to Dr. Marcella D'Souza and Mr. Crispino Lobo for their support and encouragement.

\section{REFERENCES}

Asgarian, A., Soffianian, A., Pourmanafi, S., 2016. Crop type mapping in a highly fragmented and heterogeneous agricultural landscape: A case of central Iran using multi-temporal Landsat 8 imagery. Comput. Electron. Agric. 127, pp. 531-540. https://doi.org/10.1016/j.compag.2016.07.019.

Becker-Reshef, I., Justice, C., Sullivan, M., Vermote, E., Tucker, C., Anyamba, A., Small, J., Pak, E., Masuoka, E., Schmaltz, J., Hansen, M., Pittman, K., Birkett, C., Williams, D., Reynolds, C., Doorn, B., 2010. Monitoring Global Croplands with Coarse Resolution Earth Observations: The Global Agriculture Monitoring (GLAM) Project. Remote Sens. 2, pp. 1589-1609. https://doi.org/10.3390/rs2061589.

Biradar, C.M., Thenkabail, P.S., Noojipady, P., Li, Y., Dheeravath, V., Turral, H., Velpuri, M., Gumma, M.K., Gangalakunta, O.R.P., Cai, X.L., Xiao, X., Schull, M.A., Alankara, R.D., Gunasinghe, S., Mohideen, S., 2009. A global map of rainfed cropland areas (GMRCA) at the end of last millennium using remote sensing. Int. J. Appl. Earth Obs. Geoinf. 11, pp. 114-129.

https://doi.org/10.1016/j.jag.2008.11.002.

Biradar, C.M., Xiao, X., 2011. Quantifying the area and spatial distribution of double- and triple-cropping croplands in India with multi-temporal MODIS imagery in 2005. Int. J. Remote Sens. 32, 367-386.

https://doi.org/10.1080/01431160903464179.

Defourny, P., Bontemps, S., Bellemans, N., Cara, C., Dedieu, G., Guzzonato, E., Hagolle, O., Inglada, J., Nicola, L., Rabaute, T., Savinaud, M., Udroiu, C., Valero, S., et al. 2019. Near realtime agriculture monitoring at national scale at parcel resolution: Performance assessment of the Sen2-Agri automated system in various cropping systems around the world. Remote Sens. Environ. 221, pp. 551-568.

https://doi.org/10.1016/j.rse.2018.11.007. 
Doraiswamy, P.C., Moulin, S., Cook, P.W., Stern, A., 2003. Crop Yield Assessment from Remote Sensing. Photogramm. Eng. Remote Sens. 69, pp. 665-674.

https://doi.org/10.14358/PERS.69.6.665.

European Space Agency, 2018. Sentinel Data Access Annual Report 2017. https://sentinel.esa.int/web/sentinel/news//article/sentinel-data-access-annual-report-2017 (1 Jan 2018).

Fritz, S., See, L., You, L., Justice, C., Becker-Reshef, I., Bydekerke, L., Cumani, R., Defourny, P., Erb, K., Foley, J., Gilliams, S., Gong, P., Hansen, M., Hertel, T., Herold, M., Herrero, M., Kayitakire, F., Latham, J., Leo, O., McCallum, I., Obersteiner, M., Ramankutty, N., Rocha, J., Tang, H., Thornton, P., Vancutsem, C., van der Velde, M., Wood, S., Woodcock, C., 2013. The Need for Improved Maps of Global Cropland. Eos, Trans. Am. Geophys. Union 94, pp. 31-32. https://doi.org/10.1002/2013EO030006.

Griffiths, P., Nendel, C., Hostert, P., 2019. Intra-annual reflectance composites from Sentinel-2 and Landsat for national-scale crop and land cover mapping. Remote Sens. Environ. 220, pp. 135-151.

https://doi.org/10.1016/j.rse.2018.10.031.

Inglada, J., Arias, M., Tardy, B., Hagolle, O., Valero, S., Morin, D., Dedieu, G., Sepulcre, G., Bontemps, S., Defourny, P., Koetz, B., 2015. Assessment of an operational system for crop type map production using high temporal and spatial resolution satellite optical imagery. Remote Sens. 7, pp. 12356-12379. https://doi.org/10.3390/rs70912356.

Kussul, N., Lavreniuk, M., Skakun, S., Shelestov, A., 2017. Deep Learning Classification of Land Cover and Crop Types Using Remote Sensing Data. IEEE Geosci. Remote Sens. Lett. 14, pp. 778-782. https://doi.org/10.1109/LGRS.2017.2681128.

Lary, D.J., Alavi, A.H., Gandomi, A.H., Walker, A.L., 2016. Machine learning in geosciences and remote sensing. Geosci. Front. 7, pp. 3-10. https://doi.org/10.1016/j.gsf.2015.07.003.

Löw, F., Michel, U., Dech, S., Conrad, C., 2013. Impact of feature selection on the accuracy and spatial uncertainty of perfield crop classification using Support Vector Machines. ISPRS J. Photogramm. Remote Sens. 85, pp. 102-119. https://doi.org/10.1016/j.isprsjprs.2013.08.007.

MAJA, 2017. Algorithm Theoretical Basis Document, ref: MAJA-TN-WP2-030 V1.0 2017/ Dec/07. https:/www.theialand.fr/sites/default/files/imce/produits/atbd_maja_071217.pdf (10 January 1018).

Mathur, A., Foody, G.M., 2008. Crop classification by support vector machine with intelligently selected training data for an operational application. Int. J. Remote Sens. 29, pp. 2227-2240. https://doi.org/10.1080/01431160701395203.

Matton, N., Canto, G., Waldner, F., Valero, S., Morin, D., Inglada, J., Arias, M., Bontemps, S., Koetz, B., Defourny, P., 2015. An Automated Method for Annual Cropland Mapping along the Season for Various Globally Distributed Agrosystems Using High Spatial and Temporal Resolution Time Series. Remote Sens. 7, pp. 13208-13232. https://doi.org/10.3390/rs71013208.
Mittal, S., 2012. Modern ICT for Agricultural Development and Risk Management in Smallholder Agriculture in India. New Delhi.

Monfreda, C., Ramankutty, N., Foley, J.A., 2008. Farming the planet: 2. Geographic distribution of crop areas, yields, physiological types, and net primary production in the year 2000. Global Biogeochem. Cycles 22, pp. 1-19. https://doi.org/10.1029/2007GB002947.

Pittman, K., Hansen, M.C., Becker-Reshef, I., Potapov, P. V., Justice, C.O., 2010. Estimating global cropland extent with multi-year MODIS data. Remote Sens. 2, pp. 1844-1863. https://doi.org/10.3390/rs2071844.

Powers, D.M, 2011. Evaluation: From Precision, Recall and FMeasure to ROC, Informedness, Markedness and Correlation; $J$. Mach. Lear. Technol., 1, pp. 37-63.

Salmon, J.M., Friedl, M.A., Frolking, S., Wisser, D., Douglas, E.M., 2015. Global rain-fed, irrigated and paddy croplands: A new high resolution map derived from remote sensing, crop inventories and climate data. Int. J. Appl. Earth Obs. Geoinf. 38, pp. 321-334. https://doi.org/10.1016/j.jag.2015.01.014.

Schmidhuber, J., Tubiello, F.N., 2007. Global food security under climate change. Proc. Natl. Acad. Sci. 104, pp. 1970319708. https://doi.org/10.1073/pnas.0701976104.

Siebert, S., Kummu, M., Porkka, M., Döll, P., Ramankutty, N., Scanlon, B.R., 2015. A global data set of the extent of irrigated land from 1900 to 2005. Hydrol. Earth Syst. Sci. 19, pp. 15211545. https://doi.org/10.5194/hess-19-1521-2015.

Skakun, S., Vermote, E., Roger, J.-C., Franch, B., 2017. Combined Use of Landsat-8 and Sentinel-2A Images for Winter Crop Mapping and Winter Wheat Yield Assessment at Regional Scale. AIMS Geosci. 3, pp. 163-186.

https://doi.org/10.3934/geosci.2017.2.163.

Teluguntla, P., Thenkabail, P., Oliphant, A., Xiong, J., Gumma, M.K., Congalton, R.G., Yadav, K., Huete, A., 2018. A 30-m landsat-derived cropland extent product of Australia and China using random forest machine learning algorithm on Google Earth Engine cloud computing platform. ISPRS J. Photogramm. Remote Sens. 144, pp. 325-340.

https://doi.org/10.1016/j.isprsjprs.2018.07.017.

Thenkabail, P., Hanjra, M., Dheeravath, V., Gumma, M., 2010. A Holistic View of Global Croplands and Their Water Use for Ensuring Global Food Security in the 21st Century through Advanced Remote Sensing and Non-remote Sensing Approaches. Remote Sens. 2, pp. 211-261.

https://doi.org/10.3390/rs2010211.

Thenkabail, P.S., Biradar, C.M., Noojipady, P., Dheeravath, V., Li, Y., Velpuri, M., Gumma, M., Gangalakunta, O.R.P., Turral, H., Cai, X., Vithanage, J., Schull, M.A., Dutta, R., 2009. Global irrigated area map (GIAM), derived from remote sensing, for the end of the last millennium. Int. J. Remote Sens. 30,pp.36793733. https://doi.org/10.1080/01431160802698919.

Waldner, F., Lambert, M.-J., Li, W., Weiss, M., Demarez, V., Morin, D., Marais-Sicre, C., Hagolle, O., Baret, F., Defourny, P., 2015. Land Cover and Crop Type Classification along the Season Based on Biophysical Variables Retrieved from Multi- 
Sensor High-Resolution Time Series. Remote Sens. 7, pp. 10400-10424. https://doi.org/10.3390/rs70810400.

Wu, B., Gommes, R., Zhang, M., Zeng, H., Yan, N., Zou, W., Zheng, Y., Zhang, N., Chang, S., Xing, Q., van Heijden, A., 2015. Global crop monitoring: A satellite-based hierarchical approach. Remote Sens. 7, pp. 3907-3933.

https://doi.org/10.3390/rs70403907.

Xiong, J., Thenkabail, P.S., Gumma, M.K., Teluguntla, P., Poehnelt, J., Congalton, R.G., Yadav, K., Thau, D., 2017. Automated cropland mapping of continental Africa using Google Earth Engine cloud computing. ISPRS J. Photogramm. Remote Sens. 126, pp. 225-244.

https://doi.org/10.1016/j.isprsjprs.2017.01.019.

Zheng, B., Myint, S.W., Thenkabail, P.S., Aggarwal, R.M., 2015. A support vector machine to identify irrigated crop types using time-series Landsat NDVI data. Int. J. Appl. Earth Obs. Geoinf.34,pp.103-112.

https://doi.org/10.1016/j.jag.2014.07.002 